\title{
Desempenho da apicultura no estado do Ceará: competitividade, nível tecnológico e fatores condicionantes
}

\author{
Ahmad Saeed Khan ${ }^{1}$ \\ Verônica Damasceno de Matos ${ }^{2}$ \\ Patrícia Verônica Pinheiro Sales Lima ${ }^{3}$
}

Resumo: A apicultura cearense vem se destacando como estratégia de sobrevivência para pequenos produtores. Esta pesquisa teve como objetivo estudar a apicultura cearense nos aspectos tecnológicos e de competitividade. Foram utilizados dados primários. Para mensuração do nível tecnológico formulou-se um índice formado pelas tecnologias de produção. Foram calculados indicadores de rentabilidade. Os principais resultados mostraram que os apicultores utilizaram, em média, $60,13 \%$ das tecnologias recomendadas. A maior contribuição coube à tecnologia de colheita e a menor contribuição, à tecnologia de gestão. A atividade apícola é bastante rentável e o nível tecnológico no estado é um fator determinante da competitividade. As inovações tecnológicas são imprescindíveis aos ganhos de competitividade desse setor.

Palavras-chaves: mel natural, tecnologia, competitividade, Ceará.

Abstract: In Ceará state, beekeeping is considered a survival strategy for small farmers. The objective of this research was to study technological aspects and competitiveness of beekeeping in the state. The cross section data was used. To measure the technological level, an index based on production technologies was elaborated. The main results showed that the beekeepers use 60.13\% of recommended technologies. Harvest technology contributed the most for the technological index development, while management technology had the lowest participation. The beekeeping is a profit providing activity. Technical level is an important factor to determine competitiveness and technological innovation are essential to the competitiveness of this sector.

Key-words: natural honey, technology, competitiveness, Ceará.

Classificação JEL: Q16, O33.

\footnotetext{
${ }^{1}$ Ph.D. Professor Titular do Departamento de Economia Agrícola da Universidade Federal do Ceará (UFC). E-mail: saeed@ufc.br

${ }^{2}$ Mestre em Economia Rural pela Universidade Federal do Ceará (UFC).

${ }^{3}$ Professora Dra. Adjunta do Departamento de Economia Agrícola da Universidade Federal do Ceará (UFC). E-mail: pvslima@ufc.br
} 
Desempenho da apicultura no estado do Ceará: competitividade, nível tecnológico e fatores condicionantes

\section{Introdução}

No Ceará, a apicultura tem adquirido um importante papel como fonte alternativa de renda para a agricultura familiar. Muitos agricultores, com o objetivo de aumentar a renda familiar, adotaram-na como atividade produtiva complementar às culturas tradicionais do feijão, milho e algodão.

Vários fatores atuam como estímulo à atividade entre os agricultores familiares. Matos (2005) aponta suas características favoráveis e compatíveis com as condições de trabalho e capital do pequeno produtor: pode ser executada como uma atividade secundária sem danos à atividade principal da propriedade; necessita de pequena área para instalação; necessita de um investimento inicial relativamente baixo; aumenta a produtividade da agricultura por meio da polinização; tem baixos custos de mão-de-obra; e possibilita a obtenção de vários produtos (mel, própolis, cera, pólen, geléia real, apitoxina, abelhas rainhas, enxames e crias e serviços de polinização) para os quais existem mercados interno e externo em crescimento.

Além disso, a localização do estado do Ceará é bastante propícia ao bom desempenho da apicultura. $\mathrm{O}$ semi-árido apresenta excelentes condições para a exploração apícola, não só pelo clima favorável, mas também pela riqueza nectarífera de sua vegetação. Nas áreas semi-áridas, onde predominam o cajueiro e a algarobeira, a importância da apicultura é ainda maior, uma vez que essas plantas são altamente melíferas, sendo muito apreciadas pelas abelhas e florescem na época mais seca do ano (outubro/novembro), quando a quase totalidade da vegetação nativa está sem folhas e frutos. O Ceará ainda tem a vantagem de estar em uma região, entre poucas do mundo, com possibilidade de produzir mel orgânico devido à existência de áreas onde não se utilizam agrotóxicos nas lavouras, além da existência de mata nativa.

A apicultura preenche todos os requisitos necessários à sustentabilidade: essa atividade produtiva é capaz de causar impactos positivos no âmbito social, econômico e ambiental. No aspecto econômico e social, ela se destaca como uma alternativa de geração de renda e ocupação do homem no campo, uma vez que a sua cadeia produtiva propicia a criação de postos de trabalho e fluxos de renda durante todo o ano, contribuindo para a melhoria da qualidade de vida e fixação do homem no meio rural. Quanto ao aspecto ecológico, a apicultura também contribui para a manutenção e preservação do meio ambiente devido à importante atuação das abelhas como polinizadores naturais de espécies nativas, favorecendo o equilíbrio do ecossistema e a manutenção da biodiversidade (PAXTON, 1995 apud FREITAS, 2003).

As maiores perspectivas econômicas da apicultura encontram-se na comercialização do mel. Dada a busca por uma alimentação saudável verifica-se uma crescente demanda interna e externa por esse produto. Em ambos os 
mercados, interno e externo, observa-se a existência de consumidores exigentes quanto à qualidade e aos preços.

No mercado interno nota-se, ainda, um baixo consumo de mel. Dados da FAO (Organização das Nações Unidas para a Alimentação e Agricultura) mostram que, em 2005, o consumo per capita de mel e seus derivados no Brasil foi de 14,6g enquanto na Suíça e Alemanha foi de 1,18 kg e de 1,08 kg, respectivamente. Em relação ao mercado externo, embora com uma participação ainda pequena na pauta de exportações, o mel de abelha apresenta-se como um produto promissor. O crescimento das suas exportações no Ceará entre 2007 e 2008 atingiu 109,1\%, o maior aumento entre todos os produtos embarcados. $\mathrm{O}$ destino das exportações concentrou-se nos Estados Unidos e Europa.

Apesar das condições de mercado favoráveis à produtividade cearense de mel, cerca de $15 \mathrm{~kg} /$ colméia/ano, é relativamente pequena se comparada a países como China (50 a $100 \mathrm{~kg} /$ colméia/ano), Argentina (30 a $35 \mathrm{~kg} / \mathrm{colméia/ano),} \mathrm{EUA}$ (32 kg/colméia/ano) e México (31 kg/colméia/ano) (SEBRAE, 2006). Esta baixa produtividade cearense se explica pela pouca utilização de recursos tecnológicos durante os processos produtivos e é mais grave entre os agricultores familiares fazendo com que estes tenham dificuldades para competir com as grandes empresas apícolas.

Dada que a produtividade está atrelada à adoção de inovações tecnológicas, torna-se relevante o conhecimento do perfil tecnológico dos pequenos produtores e dos fatores que influenciam sua decisão de adotar ou não uma determinada tecnologia para torná-los mais competitivos. Diante do exposto, o presente artigo tem como objetivos: a) identificar o nível tecnológico empregado pelos apicultores cearenses; $b$ ) verificar quais as tecnologias que mais contribuem na determinação do nível tecnológico da apicultura; c) verificar a influência das características socioeconômicas dos apicultores cearenses no nível tecnológico; d) analisar a competitividade dos apicultores; e e) estudar a relação existente entre competitividade e nível tecnológico da produção de mel dos apicultores.

\section{Aspectos teóricos}

\subsection{Competitividade e seus indicadores}

Os estudos recentes têm em comum a ausência de consenso quanto à definição em termos de conceito e metodologias adequadas de avaliação da competitividade (FERRAZ et al., 1995). Mas, a idéia de competitividade está, de uma forma geral, ligada à capacidade da empresa ou país em dominar uma parcela do mercado (STULP, 1993).

Muitos autores vêem a competitividade como um fenômeno diretamente relacionado às características da firma ou produto, o que gera a sua definição sob 
Desempenho da apicultura no estado do Ceará: competitividade,

nível tecnológico e fatores condicionantes

a ótica do desempenho de mercado e da eficiência do processo produtivo implementada pela firma (COUTINHO e FERRAZ, 1995).

Segundo Pinheiro, Moreira e Horta (1992), há três conceitos diferentes para avaliar o grau de competitividade de uma economia: conceitos macro, de eficiência e de desempenho.

Os "conceitos macros" consideram variáveis relacionadas a decisões de políticas, como subsídio e incentivos às exportações e taxa de câmbio. Esse enfoque atribui grande importância à desvalorização cambial como forma de ganhar competitividade e apresenta como indicadores macroeconômicos tradicionais a taxa de câmbio efetiva real e a relação câmbio/salário real e câmbio/custo real (SEREIA et al., 2002).

A competitividade revelada ex post (desempenho) está relacionada às vantagens comparativas, estabelecidas de forma indireta através dos fluxos do comércio internacional. Por meio de medidas de algo que já aconteceu (ex post), expressa a participação do mercado ("market-share"), em que são competitivas as empresas, indústrias ou países que ampliam sua participação na oferta de determinado produto em um certo momento do tempo (HAGUENAUER et al., 1996).

A competitividade potencial ex ante (eficiência) é explicada através da relação insumo-produto praticada pela firma, evidenciando sua capacidade de converter insumos em produtos com o máximo de rendimento. Esse conceito está relacionado à idéia de vantagens competitivas, que dependem do uso mais produtivo dos insumos, que, por sua vez, requer constantes inovações (SEREIA et al., 2002). A competitividade é definida pelo produtor, que determina as técnicas maximizadoras de seu grau de capacitação a fim de implementar estratégias de adequação aos padrões concorrenciais do mercado específico que lhe permitam ampliar ou conservar, de forma duradoura, uma posição sustentável no mercado (HAGUENAUER et al., op. cit) .

Segundo Sereia et al. (op. cit), o "produtor ao escolher as técnicas que utiliza, submetido às restrições impostas por sua capacidade tecnológica, gerencial, financeira e comercial, estará definindo sua competitividade". Para Ferraz et al. (1995) é o produtor que define a sua competitividade ao escolher as técnicas que utiliza. O desempenho no mercado é uma conseqüência da capacitação tecnológica, gerencial, financeira e comercial. Sendo assim, considerou-se neste estudo que a competitividade da apicultura cearense corresponde ao uso de tecnologias adequadas para a produção de mel que, por sua vez, é função da adoção de inovações tecnológicas.

A adoção de inovações tecnológicas, portanto, é condicionada por características econômicas e sociais dos produtores. 


\subsection{Inovações tecnológicas e seus fatores condicionantes}

Dentro de diferentes linhas do pensamento econômico, a tecnologia desempenha importante papel para o desenvolvimento econômico e as inovações tecnológicas constituem o condicionante fundamental para esse desenvolvimento ao aumentar a produtividade dos fatores de produção (SILVA, 1995). Nesta abordagem, inserir a variável tecnologia em estudos voltados para aumentar a produtividade do setor apícola é uma condição necessária ao desenvolvimento da atividade.

Entre os muitos economistas que abordaram esse tema, Smith (1983) enfatizou que as mudanças tecnológicas associadas ao processo de divisão do trabalho constituem os fatores determinantes do aumento da produtividade. Para Karl Marx, a adoção das inovações tecnológicas é motivada pela competição entre os capitalistas e é responsável pela dinâmica do processo de acumulação (SOUZA, 2000). Shumpeter defendeu a tecnologia como elemento essencial à dinâmica capitalista, uma vez que a mesma é responsável por mudanças no comportamento dos agentes econômicos, na relação de recursos, na destruição dos métodos tradicionais de produção e pela melhoria qualitativa na estrutura econômica (SILVA, op. cit). Na teoria de Hicks (1936), as inovações tecnológicas são induzidas pela escassez dos fatores produtivos.

Os trabalhos mais recentes que versam sobre o assunto visam captar os impactos que a tecnologia ou as inovações tecnológicas exercem sobre a economia. Algumas pesquisas objetivam conhecer o papel da tecnologia sobre a geração de riqueza e os efeitos distributivos dos seus benefícios entre os agentes econômicos; outras, mensurar o nível de tecnologia adotado pelos setores econômicos.

Visando orientar programas de transferência de tecnologias para agricultores, Santos (1977) buscou identificar os fatores que influenciam a adoção de práticas agropecuárias no estado de Minas Gerais através de um modelo que explica a adoção de tecnologia por meio de cadeias causais. O modelo pressupõe que a adoção é influenciada diretamente por algumas variáveis consideradas de primeiro nível, sendo estas, por sua vez, influenciadas por outras em segundo nível e, assim, formam-se cadeias até um quarto nível de influência. O nível tecnológico adotado foi especificado por um índice indicado pelo número de práticas adotadas pelo agricultor. Foram atribuídos os escores: um (1) quando o agricultor utilizava certa prática e zero (0) quando isso não acontecia. O índice tecnológico foi obtido pelo somatório das práticas utilizadas. A partir disto, o autor procurou identificar os fatores culturais, sociais e econômicos que explicassem a adoção das práticas agrícolas e que outros fatores poderiam explicar os primeiros e assim sucessivamente até um quarto nível de fatores explicativos. 
Desempenho da apicultura no estado do Ceará: competitividade, nível tecnológico e fatores condicionantes

No trabalho de Monteiro et al. (1980), os autores mostraram que a adoção e a difusão de técnicas modernas são orientadas não somente pelas características do produtor, mas também pelo tipo de produto que esse cultiva. O nível tecnológico foi mensurado pelo somatório dos valores dos insumos e equipamentos utilizados no processo produtivo, sendo esse classificado em alto, médio-superior, médio-inferior e baixo. Foi observada a correlação entre nível tecnológico e diversificação agrícola, linha de exploração, posse da terra, tamanho da unidade produtiva e nível de vida dos produtores.

De acordo com Burke e Molina Filho (1982) é no nível de percepção do agricultor que devem ser buscadas, na sua maior parte, as explicações causais para os comportamentos manifestos, de adoção e não-adoção de inovações tecnológicas. Para esses autores "a percepção das características das inovações e dos vários fatores situacionais, sociais, pessoais etc., que envolvem a adoção de uma inovação ou conjunto de inovações, é, em última análise, a determinante imediata do comportamento final manifesto do agricultor".

Ao analisar os fatores determinantes da adoção de tecnologias na cajucultura, Carbajal (1991) utilizou o modelo teórico de adoção de inovações de Burke e Molina Filho (op. cit), apud Carbajal (op. cit). Nesse modelo, pressupõe-se a existência de dois tipos de variáveis no processo de adoção: variáveis internas, que descrevem o indivíduo através de aspectos comportamentais, de comunicação e psicosociológicos, e variáveis externas, aquelas que envolvem aspectos econômicos, estruturais, políticos, organizacionais e as qualidades intrínsecas das tecnologias, que, a partir de seus efeitos, podem influenciar na decisão de adotá-las. O comportamento do indivíduo resulta da interação dessas variáveis e a adoção ou rejeição de tecnologias reflete o comportamento manifesto final derivado dessa interação.

Em seu estudo, Carbajal (op. cit) fez uso de dois índices, um para medir o nível tecnológico e outro, o grau de adoção. No primeiro, foi considerado se o produtor conhecia ou não as tecnologias recomendadas e a importância relativa de cada tecnologia para a produção do caju. No índice do nível de adoção, foram consideradas a utilização correta ou incorreta das tecnologias e, também, sua importância relativa. Esses dois índices foram considerados como variáveis dependentes e suas variáveis independentes foram as características sócio-econômicas dos produtores e as condições estruturais em que esses se encontravam inseridos.

Vicente (1997), visando identificar os fatores que determinam a adoção de tecnologia na agricultura paulista, definiu o processo de adoção de tecnologia de forma agregada como a disseminação de uma nova tecnologia por uma região, sendo este medido pelo nível de uso de uma determinada área geográfica ou população. Os fatores condicionantes da adoção de tecnologia foram divididos pelo autor em estruturais, conjunturais e ambientais. Os primeiros foram caracterizados como fatores com maior rigidez no curto prazo, cuja dotação pode 
prevalecer por diversos períodos produtivos e com maior dificuldade para ser alterada por medidas de políticas governamentais. Os conjunturais, podem sofrer mais facilmente interferências de políticas agrícolas. Os fatores ambientais compreendem tanto os fatores modificáveis quanto os outros, cujas restrições podem ser apenas contornáveis com alterações na composição das explorações. O índice tecnológico foi mensurado atribuindo o valor um (1) ou zero (0) para utilização ou não de tecnologias, somando-os posteriormente.

Para Mesquita (1998), a adoção de tecnologia é explicada por fatores subjetivos e objetivos. Os fatores subjetivos são o conhecimento parcial ou total da tecnologia, a percepção da tecnologia como uma "solução" e a avaliação por parte do produtor de que a tecnologia elevará seu bem-estar material. Os fatores objetivos referem-se à impossibilidade ou impotência devido aos limitados recursos econômicos e naturais de que dispõem. Neste último caso, mesmo que o agricultor conheça a tecnologia e tenha a expectativa que ela lhe trará bons resultados não dispõem de condições essenciais para adotá-la.

No trabalho realizado por Souza (op. cit) foi analisado o nível tecnológico da agricultura familiar no Ceará. A pesquisa teve por objetivo conhecer os fatores sócio-econômicos dos agricultores familiares que explicassem a existência de diferença interna de adoção tecnológica, ou seja, a presença de níveis tecnológicos diferentes entre unidades de produção de uma mesma região, sendo ainda relacionado o nível tecnológico ao diferencial de produtividade das unidades de produção. O índice do nível tecnológico foi mensurado considerando o número de técnicas utilizadas pelo agricultor e admitindo a importância relativa destas técnicas dentro do pacote tecnológico determinado como o necessário.

Avaliando os fatores que determinam a adoção de tecnologia para um grupo de produtores rurais do estado de São Paulo, Silva e Carvalho (2002) utilizaram o método da contagem para verificar a adoção de um número de tecnologias no processo produtivo. Variáveis estruturais e conjunturais foram utilizadas como variáveis explicativas do modelo. As primeiras foram consideradas como variáveis que não podem ser alteradas no curto prazo, e as conjunturais estariam associadas a um programa de formação de empreendedores. A variável de resposta incluiu mudanças de atividade, de cultura, de produtividade e de agregação de valores no processo produtivo.

Outro ponto em comum nos trabalhos citados é a utilização de fatores socioeconômicos como variáveis explicativas do nível tecnológico adotado pelos produtores. Isto deve-se ao fato de que a adoção de tecnologias é uma variável qualitativa e é condicionada por características econômicas e sociais, como também subjetivas dos produtores. Estas características influenciam na percepção de mundo do agricultor e na forma como ele enxerga os problemas e encontra formas de solucioná-los, como bem enfatizaram Burke e Molina Filho (op. cit.). 
Desempenho da apicultura no estado do Ceará: competitividade, nível tecnológico e fatores condicionantes

A associação dos conceitos discutidos em 2.1. e 2.2. apontam a associação entre inovações tecnológicas e competitividade. Neste estudo, admite-se que as inovações tecnológicas aumentam a produtividade dos produtores e melhoram a qualidade do produto promovendo aumentos na rentabilidade e ganhos de competitividade.

\subsection{Inovações tecnológicas e competitividade}

Segundo Possas e Carvalho (1994), o progresso tecnológico é capaz de construir e destruir as vantagens competitivas. Para que uma firma seja competitiva, não é suficiente deter vantagens estáticas; é preciso ter capacidade de estar sempre à frente, recriando tais vantagens. Para isso, deve-se ter conhecimento da tecnologia, investir em pesquisa e desenvolvimento (P\&D) e em recursos humanos qualificados.

A complexidade das cadeias produtivas e o acirramento da concorrência impõem às empresas desafios quanto à construção e à manutenção de posições competitivas. Em particular, estes desafios se relacionam com estratégias de introdução ou adaptação de novas tecnologias. Portanto, a manutenção de posições competitivas em qualquer mercado se faz com base em inovações tecnologias referentes ao produto, ao processo produtivo e à gestão. Existe uma relação positiva e direta entre inovações tecnológicas e competitividade, uma vez que a primeira possui grande poder de determinação sobre a segunda.

A capacidade de ação estratégica e os investimentos em inovações de processo e produto determinam a competitividade futura (FARINA e ZYLBERSZTAJN, 1994). O investimento em projetos de P\&D é uma atribuição exclusiva das empresas como forma de manter a competitividade no mercado e o financiamento desses projetos é função dos resultados obtidos pela empresa por meio da introdução das inovações (BARDY, 2000).

Há, ainda, uma linha de pesquisa que trata da capacidade das empresas em se apropriar de avanços tecnológicos como forma de estratégia de competitividade nos mercados, tendo em vista que a constante inovação tecnológica em uma empresa determina a criação ou manutenção da competitividade desta numa região (MIRANDA, 2001).

Um avanço da economia para uma posição mais competitiva no mercado internacional requer uma combinação entre políticas industriais ligadas às necessidades de capacitação da indústria, com investimentos em $P \& D$, e às estratégias microeconômicas de inovações tecnológica e gerencial (SEREIA et al., op. cit).

Para Freitas (2003) e Matos (2005), os apicultores que reduzem seus custos unitários de produção pelo uso adequado de tecnologias aumentam sua lucratividade e competitividade em relação aos demais que tiveram seu custo unitário mantido devido a não utilização ou utilização parcial das tecnologias recomendadas. 


\section{Material e métodos}

\section{1. Área geográfica de estudo e tamanho da amostra}

Nesta etapa do trabalho, foram selecionados sete municípios do estado do Ceará: Santana do Cariri e Crato (na microrregião do Cariri), Pacajus (na microrregião de Pacajus), Chorozinho (na microrregião de Chorozinho), Limoeiro do Norte e Alto Santo (na microrregião do Baixo Jaguaribe) e Mombaça (na microrregião do Sertão de Senador Pompeu).

Esses municípios foram escolhidos para a realização da pesquisa, por serem os que apresentaram nos anos mais recentes, de acordo com dados do IBGE, as maiores produções de mel no Ceará, destacando-se entre os 10 principais municípios produtores no estado. Em cada um dos municípios citados foram entrevistados 15 produtores de mel, totalizando uma amostra de 105 produtores.

\subsection{Levantamento dos dados}

Os dados utilizados nesta pesquisa foram de origem primária, obtidos através de aplicações de questionário junto aos apicultores selecionados nos sete municípios que compõem a amostra total, nos meses de fevereiro, maio e junho de 2004. Todas as informações coletadas foram referentes ao ano de 2003.

$\mathrm{Na}$ elaboração do questionário, foram consideradas as informações referentes à tecnologia recomendada, à produção, à comercialização e aos custos de produção.

\subsection{Método de análise}

\subsubsection{Mensuração do nível tecnológico}

No cálculo do nível tecnológico dos produtores de mel utilizou-se a metodologia empregada por Freitas (2003). Para tanto, foram considerados os equipamentos e as técnicas indicadas como mais adequadas ${ }^{4}$ à atividade apícola, levando-se em consideração a segurança dos apicultores, a qualidade do produto, os ganhos de produtividade e competitividade, a redução do tempo de trabalho e dos custos. O Quadro 1 apresenta as variáveis adotadas no cálculo dos índices tecnológicos dos apicultores pesquisados.

\footnotetext{
$\overline{{ }^{4} \text { As informações }}$ referentes às tecnologias recomendadas foram obtidas junto ao Departamento de Zootecnia, Setor de Apicultura da Universidade Federal do Ceará (UFC). Um detalhamento de cada uma delas encontra-se em Matos (2005) disponível no endereço: http://www.economiarural.ufc.br/veronica2005.pdf.
} 
Desempenho da apicultura no estado do Ceará: competitividade, nível tecnológico e fatores condicionantes

Quadro 1. Tecnologias adotadas no cálculo do Índice Tecnológico dos apicultores e suas respectivas variáveis.

\begin{tabular}{|c|c|}
\hline Tecnologias adotadas & Variáveis \\
\hline $\begin{array}{l}\text { Tecnologia de } \\
\text { equipamentos }\end{array}$ & $\begin{array}{l}\text { - Indumentária; } \\
\text { - Fumigador; } \\
\text { - Formão; } \\
\text { - Vassourinha; } \\
\text { - Colméia; } \\
\text { - Centrífuga inox; } \\
\text { - Decantador inox; } \\
\text { - Mesa desoperculadora inox; } \\
\text { - Peneirainox; } \\
\text { - Tela excluidora de rainha; } \\
\text { - Carretilha, incrustador ou bateria; }\end{array}$ \\
\hline $\begin{array}{l}\text { Tecnologia } \\
\text { de manejo }\end{array}$ & $\begin{array}{l}\text { - Substituição da abelha rainha; } \\
\text { - Substituição de ceraalveolada; } \\
\text { - Controle de enxameação; } \\
\text { - Divisão de enxames; } \\
\text { - Desobstrução dos ninhos; } \\
\text { - Colocação de melgueiras para as abelhas depositarem o mel; } \\
\text { - Reserva de alimento; } \\
\text { - Combate a traças e/ou formigas; } \\
\text { - Alimentação artificial; } \\
\text { - Criação de espaço para ventilação; } \\
\text { - Colocação das colméias em locais sombreados; } \\
\text { - Distância das colméias aos locais de água; }\end{array}$ \\
\hline $\begin{array}{l}\text { Tecnologia } \\
\text { de colheita }\end{array}$ & $\begin{array}{l}\text { - Uso de fumaça na melgueira durante a colheita de mel; } \\
\text { - Procedimento para retirada das abelhas dos quadros; } \\
\text { - Garfo desoperculador; } \\
\text { - Casa do mel; } \\
\text { - Transporte de melgueiras; }\end{array}$ \\
\hline $\begin{array}{l}\text { Tecnologia de } \\
\text { pós-colheita }\end{array}$ & $\begin{array}{l}\text { - Uso de equipamentos de higiene; } \\
\text { - Armazenamento de mel; } \\
\text { - Recipientes para armazenamento do mel; } \\
\text { - Fracionamento de mel; }\end{array}$ \\
\hline $\begin{array}{l}\text { Tecnologia } \\
\text { de gestão }\end{array}$ & $\begin{array}{l}\text { - Contrato de prestação de serviços em geral; } \\
\text { - Pesquisa sobre tendências de mercado; } \\
\text { - Treinamento do apicultor; } \\
\text { - Treinamento de funcionários; } \\
\text { - Controle de qualidade; } \\
\text { - Parceria em pesquisas; } \\
\text { - Parcerias na comercialização; } \\
\text { - Uso de marketing na comercialização; } \\
\text { - Uso de computador; } \\
\text { - Uso da informática para obter informações de mercado; } \\
\text { - Uso da informática para atendimento ao cliente. }\end{array}$ \\
\hline
\end{tabular}

Fonte: Elaboração própria. 
Para o cálculo dos índices tecnológicos, foi utilizada a metodologia sugerida por Miranda (2001), conforme abaixo.

Índice tecnológico do apicultor $j$ relativo à tecnologia $n\left(I_{n j}\right)$ :

$I_{j}=\sum_{i=y}^{m} \frac{a_{i}}{w_{n}}$

sendo $, w_{n}=\max \sum_{i=y}^{m} a_{i}, 0 \leq \operatorname{In} n_{j} 1$

e ainda:

$n=n$-ésima tecnologia $(n=1, \ldots v)$;

$v=$ número de tecnologias;

$j=j$-ésimo apicultor $(j=1, \ldots, z)$;

$z=$ número de apicultores;

$a_{i}=$ valor atribuído à variável $x_{i}$ da tecnologia $n$;

$i=$ é o elemento de indexação das variáveis que compõem a tecnologia $n,(i=y, \ldots, m)$;

$\frac{a_{i}}{w_{n}}=$ peso de cada variável $x_{i}$ na composição do índice da tecnologia $n$.

Para a tecnologia de uso dos equipamentos, $n=1, i=1, \ldots, 11$ e $w_{1}=17$. Tecnologia de manejo, $n=2, i=12, \ldots, 23$ e $w_{2}=20$. Tecnologia de colheita, $n=3, i$ $=24, \ldots, 28$ e $w_{3}=8$. Tecnologia de pós-colheita, $n=4, i=29, \ldots, 32$ e $w_{4}=6$. Tecnologia de gestão, $n=5, i=33, \ldots, 42$ e $w_{5}=11$.

O índice tecnológico geral médio dos apicultores em relação à tecnologia $n\left(I T_{n}\right)$ é o resultado do somatório dos $I n_{j}$ de uma tecnologia específica dividido pelo número de apicultores, conforme abaixo:

$$
I T_{n}=\frac{1}{z} \sum_{j=1}^{z} \sum_{i=y}^{m} \frac{a_{i}}{w_{n}}=\frac{1}{z} \sum_{j=1}^{z} I n_{j}
$$

O índice tecnológico geral do apicultor $j$, é calculado por meio da média aritmética simples dos $I_{n j}$ 's, englobando todas as tecnologias.

$$
I P_{j}=\frac{1}{v} \sum_{n=1}^{v} I_{n j}
$$

O índice tecnológico geral $(I G)$ da produção de mel é o resultado do somatório dos ITn de todas as tecnologias divididas pelo número de tecnologias. O IG também é o somatório dos $I P_{j}$ de todos apicultores dividido pelo número de apicultores conforme abaixo:

$$
I G=\frac{1}{z} \sum_{j=1}^{z} I P_{j}=\frac{1}{v} \sum_{n=1}^{v} I T_{n}
$$


Os níveis tecnológicos dos apicultores são determinados com base nos índices já citados. Esses índices variam entre um (1) e zero (0). Quanto mais próximo de um (1) melhor o nível tecnológico.

Para a comparação dos níveis tecnológicos entre os apicultores foram definidos os seguintes padrões com base nos intervalos de variação dos valores dos índices: alto nível tecnológico: $0,8<I \leq 1$; médio nível tecnológico: $0,5<I \leq 0,8$ e baixo nível tecnológico: $0 \leq I \leq 0,5$; em que o $I$ é o valor de um índice especificado.

O padrão alto nível tecnológico classifica os apicultores que utilizam mais de $80 \%$ da tecnologia recomendada. O padrão médio nível tecnológico é atribuído aos apicultores que empregam entre $50 \%$, exclusive, e $80 \%$, inclusive, da tecnologia recomendada. E, finalmente, o padrão baixo nível tecnológico é conferido aos apicultores que usam $50 \%$, ou menos da tecnologia recomendada.

\subsubsection{Influência das características socioeconômicas no nível tecnológico}

A relação entre o nível tecnológico e as características socioeconômicas dos produtores de mel foi analisada a partir de um modelo de respostas binárias, aquele em que a variável dependente $(Y)$ assume valores discretos e a probabilidade de ocorrência de cada resposta binária é uma função de um conjunto de atributos $(X)$ tais como grau de instrução, local de residência, assistência técnica, participação em organização social, acesso ao financiamento, experiência com a atividade, objetivo com a atividade, disponibilidade de mão-de-obra, etc.

Por se tratar de um modelo em que a variável dependente é uma variável dicotômica, fez-se uso do Modelo Probit, em que a resposta binária para um indivíduo depende de um índice de utilidade ${ }^{5}$ não observável $I_{i}$ (GUJARATI, 2000). Logo,

$$
I_{i}=\beta_{1}+\beta_{2} X_{2 i}+\ldots+\beta_{j} X_{j i}+\ldots+\beta_{k} X_{k i}+u_{i}=X_{i}^{\prime} \beta+u_{i}
$$

em que $X_{j i}$ é a j-ésima variável explicativa associada à resposta binária do $i$-ésimo apicultor, $(i=1,2, \ldots, n ; j=1,2, \ldots, k), X_{i}$ é um vetor $(\mathrm{kx} 1)$ de variáveis explicativas, $\beta$ é um vetor $(\mathrm{kx} 1)$ de parâmetros a serem estimados e $u_{i}$ é o termo de perturbação estocástica.

\footnotetext{
${ }^{5}$ Para o desenvolvimento do modelo, assume-se que existe uma utilidade derivada da escolha por um indivíduo, baseada nas variáveis explicativas. Essa utilidade é definida por uma utilidade média mais um termo de perturbação estocástica. $O$ índice de utilidade é a diferença entre as utilidades associadas as duas possíveis escolhas. Ou seja, $I_{i}=U_{i 1}-U_{i 0}$, em que $U_{i 1}$ é a utilidade associada a $Y_{i}=1$ e $U_{i 0}$ é a utilidade relacionada a $Y_{i}=0$ (JUDGE, 1988).
} 
Os valores observados da variável binária foram estabelecidos da seguinte forma (JUDGE, 1988):

$$
Y_{i}=1 \text {, se } I_{i}>0 \text { e } Y_{i}=0 \text {, se } I_{i} \leq 0
$$

em que $I_{i}=0$ é o nível crítico ou limiar que determina a mudança de qualidade na resposta.

Neste trabalho, a relação de correspondência entre os valores assumidos pelo índice tecnológico geral do apicultor $\left(I P_{j}\right)$ e os valores dicotômicos 0 e 1 foi estabelecida da seguinte forma: para valores desse índice maiores ou iguais ao índice tecnológico geral da produção de mel $(I G)$, associou-se à variável dependente o valor binário um (1) e caso contrário o valor zero (0).

$Y_{i}$ é uma função não-linear do índice de utilidade dada por:

$$
Y_{i}=g\left(I_{i}\right)=g\left(X_{i}^{\prime} \beta+u_{i}\right)
$$

a probabilidade de $Y_{i}=1$ dado que $X_{i}$ ocorreu é:

$$
P_{i}(1)=\operatorname{Pr}\left(Y_{i}=1 \mid X_{i} \beta\right)=\operatorname{Pr}\left(I_{i}>0\right)=\operatorname{Pr}\left(u_{i}>-X_{i}^{\prime} \beta\right)
$$

Nesse modelo, assume-se que $u_{i}$ tem distribuição normal padrão ${ }^{6}$ e que a função Probit é uma função de densidade acumulativa normal dada por:

$$
P_{i}=F_{u}\left(X^{\prime} \beta\right)=\frac{1}{\sqrt{2 \pi}} \int_{-\infty}^{X_{i}^{\prime} \beta} e^{\frac{-t^{2}}{2}} d t=E\left(Y_{i} \mid X_{i}, \beta\right)
$$

no qual $t$ é a variável $u$ padronizada.

A variável binária assume a seguinte forma:

$$
Y_{i}=F_{u}\left(X_{i}^{\prime} \beta\right)+\varepsilon_{i}
$$

em que $\varepsilon_{i}$ é um resíduo representando o desvio da variável binária $Y_{i}$ de sua média condicional.

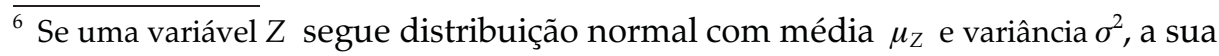
função densidade acumulativa é: $F\left(Z_{0}\right)=\int_{-\infty}^{Z_{0}} \frac{1}{\sqrt{2 \pi \sigma}} e^{\frac{-\left(Z-\mu_{Z}\right)^{2}}{2 \sigma^{2}}}=\frac{1}{\sqrt{2 \pi}} \int_{-\infty}^{Z_{0}} e^{\frac{-t^{2}}{2}}$, em que $\mathrm{t} \sim N(0,1)$.

${ }^{7} E\left(Y_{i} \mid X_{i}, \beta\right)=1 \cdot \operatorname{Pr}\left(Y_{i}=1 \mid X_{i}, \beta\right)+0 \cdot \operatorname{Pr}\left(Y_{i}=0 \mid X_{i}, \beta\right)=\operatorname{Pr}\left(Y_{i}=1 \mid X_{i}, \beta\right)$ 
Como nesse trabalho a amostra é composta de observações individuais, fez-se uso do Método de Máxima Verossimilhança para a estimação dos parâmetros do modelo. Esse método objetiva estimar parâmetros que maximizam a probabilidade de uma determinada amostra pertencer a uma determinada população. Dada uma amostra de $n$ observações independentes, a função de máxima verossimilhança é

$$
L=\prod_{i=1}^{n} f\left(Y_{i}\right)=\prod_{i=1}^{n} P_{i}^{Y_{i}}\left(1-P_{i}\right)^{1-Y_{i}}=\prod_{i=1}^{n} F\left(X_{i}^{\prime} \beta\right)^{Y_{i}}\left[1-F\left(X_{i}^{\prime} \beta\right)\right]^{1-Y_{i}}
$$

Para verificar a existência de heterocedasticidade utilizou-se o teste do Multiplicador de Lagrange, que aplica uma aproximação por uma série de Taylor de primeira ordem à equação (11).

\subsubsection{Análise de rentabilidade financeira e de competitividade da produção de mel natural ${ }^{8}$}

A análise de rentabilidade financeira e de competitividade dos apicultores foi feita levando-se em conta os custos da produção de mel natural e os indicadores de rentabilidade conforme a metodologia utilizada no desenvolvimento do Custagri (Sistema Integrado de Custos Agronômicos).

Foram utilizados os seguintes indicadores descritos a seguir.
a) Custo operacional efetivo (COE)
b) Custo total (COT)
c) Depreciação
d) Manutenção
e) Encargos financeiros
f) Outras despesas
g) Custo total de produção (CTP)
h) Custo médio $\left(\mathrm{C}_{\mathrm{Me}}\right)$
i) Receita bruta $(\mathrm{RB})$
j) Fluxo de caixa (FC)
k) Margem bruta (MB)
1) Ponto de nivelamento
m) Lucro operacional (LO)
n) Índice de lucratividade (IL)

\footnotetext{
${ }^{8}$ A análise de custos e rentabilidade foi feita como base em uma unidade de comparação equivalente a $25 \mathrm{~kg}$ de mel.
} 


\subsubsection{Relação entre nível tecnológico e competitividade}

A relação entre competitividade e nível tecnológico dos apicultores foi calculada a partir de uma regressão linear simples, utilizando o método dos Mínimos Quadrados Ordinários (MQO). A competitividade foi considerada como variável dependente do nível tecnológico. Utilizou-se o índice de lucratividade (IL) como variável dependente e o índice tecnológico geral do produtor $\left(I P_{3 j}\right)$ como variável independente.

\section{Resultados e discussão}

\section{1. Índice tecnológico geral da produção de mel natural}

A Tabela 1 apresenta o índice tecnológico médio e o respectivo desvio padrão para cada tecnologia separadamente. Como pode ser observado, é na colheita que os apicultores apresentam maior percentual de adoção de tecnologias recomendadas $(81,19 \%)$. Por outro lado, apenas $22,77 \%$ das tecnologias de gestão recomendadas foram implantadas. Quanto às tecnologias de equipamentos, manejo e pós-colheita, pode-se notar um padrão tecnológico médio com índices iguais a 0,$7159 ; 0,6139$ e 0,6340 , respectivamente.

Tabela 1. Índice tecnológico geral médio dos apicultores em relação à tecnologia recomendada $\left(I T_{n}\right)^{9}$ e respectivo desvio padrão - Ceará, 2003.

\begin{tabular}{ccc}
\hline Tecnologia & Índice Médio & Desvio Padrão \\
\hline Equipamentos & 0,7156 & 0,1321 \\
Manejo & 0,6139 & 0,1478 \\
Colheita & 0,8119 & 0,1500 \\
Pós-Colheita & 0,6340 & 0,2265 \\
Gestão & 0,2277 & 0,1272 \\
\hline
\end{tabular}

Fonte: Dados da pesquisa.

O valor do índice tecnológico da tecnologia de manejo $(0,6139)$ é conseqüência do baixo desempenho da maioria dos apicultores devido à pouca utilização de técnicas adequadas de manejo. Observou-se que 57,33\%, 64,95\% e $93 \%$ dos apicultores não fizeram, respectivamente, a substituição da abelha rainha, a divisão dos enxames e a construção de espaços para ventilação das colméias, respectivamente.

\footnotetext{
${ }_{9}$ Tecnologia recomendada conforme Quadro 1. Índice médio igual 1 significa que o apicultor utiliza corretamente $100 \%$ da tecnologia recomendada.
} 
Desempenho da apicultura no estado do Ceará: competitividade, nível tecnológico e fatores condicionantes

O relativamente baixo valor do índice de pós-colheita $(0,6340)$ é principalmente atribuído ao fato de que $20,62 \%$ dos apicultores entrevistados não utilizaram nenhum dos itens que compõem essa tecnologia e também a maioria deles não armazenou o mel protegido da umidade e do calor. Observou-se, ainda, que 79,38\% deles fracionaram o mel manualmente, direto do decantador. Esse procedimento é justificado pela pequena produção da maioria dos apicultores.

Em relação à tecnologia de gestão, o baixo valor obtido é justificado pelo não uso da informática, ausência de parcerias com instituições de pesquisa, ausência de contratação de serviços e marketing e falta de treinamento de empregados.

De modo geral, os resultados retratados na Tabela 1 são reflexos da assistência técnica deficiente, do baixo grau de escolaridade, do baixo nível de capital social e das dificuldades de acesso a crédito dos apicultores.

Analisando-se os índices tecnológicos gerais por conjunto e tecnologias: $I G_{1}$, $I G_{2}$ e $I G_{3}$, na Tabela $2^{10}$, nota-se que, em 2003, os apicultores tiveram um nível tecnológico médio de produção $\left(I G_{1}\right)$ em torno de $71,36 \%$ das tecnologias recomendadas, considerando-se as tecnologias de equipamentos, manejo e colheita.

A inclusão da tecnologia de pós-colheita nas tecnologias de produção reduziu o valor do índice geral para $0,6938\left(I G_{2}\right)$. Esse comportamento deve-se ao fato de que o índice tecnológico médio para a tecnologia de pós-colheita foi menor para as tecnologias do $I G_{1}$.

O índice tecnológico geral para as tecnologias de produção + pós-colheita e gestão $\left(I G_{3}\right)$ foi de 0,6013 , inferior a $I G_{1}$ (índice tecnológico de produção) e $I G_{2}$.(índice para tecnologia de produção + pós-colheita). A tecnologia de gestão foi a que menos concorreu na formação desse índice, conforme apresentado na Tabela 3. Nesta Tabela estão inseridas informações sobre a contribuição absoluta e relativa das tecnologias de equipamento, manejo, colheita, pós-colheita e gestão de produção de mel na composição do índice tecnológico.

Considerando a tecnologia de produção, a tecnologia de colheita apresentou $37,92 \%$ do índice tecnológico geral $\left(I G_{1}\right)$. A tecnologia de manejo teve menor participação na formação desse índice geral. Analisando o índice tecnológico geral $\left(I G_{2}\right)$, observou-se a maior participação de tecnologia de colheita e a menor contribuição de tecnologia de manejo na composição desse índice.

\footnotetext{
${ }^{10} \mathrm{~A}$ identificação numérica nesses indicadores representa as três etapas em que foram calculados: 1) considerando as três primeiras tecnologias: equipamentos, manejo e colheita; 2) além destas, a tecnologia de pós-colheita; 3) englobando as cinco tecnologias.
} 
Tabela 2. Valores médio (Índice tecnológico geral ( $I G)$, mínimo, máximo e desvio padrão do índice tecnologia do apicultor $\left(I P_{j}\right)$ em relação ao diferente conjunto de técnicas usadas na produção de mel natural - Ceará, 2003.

\begin{tabular}{lcccc}
\hline Tecnologia & $\begin{array}{c}\text { Índice } \\
\text { Tecnológico }\end{array}$ & $\begin{array}{c}\text { Valor } \\
\text { Mínimo }\end{array}$ & $\begin{array}{c}\text { Valor } \\
\text { Máximo }\end{array}$ & $\begin{array}{c}\text { Desvio } \\
\text { Padrão }\end{array}$ \\
\hline $\begin{array}{l}\text { Tecnologia de produção }\left(I G_{1}\right) \\
\text { (equipamento, manejo e colheita) }\end{array}$ & 0,7136 & 0,3897 & 0,9304 & 0,1106 \\
$\begin{array}{l}\text { Tecnologia de produção }+ \\
\text { pós-colheita }\left(I G_{2}\right)\end{array}$ & 0,6938 & 0,3756 & 0,9478 & 0,1262 \\
$\begin{array}{l}\text { Tecnologia de produção }+ \\
\text { pós-colheita + gestão }\left(I G_{3}\right)\end{array}$ & 0,6013 & 0,3005 & 0,8128 & 0,1130 \\
\hline
\end{tabular}

Fonte: Resultados da pesquisa.

Verificando a contribuição das tecnologias de produção, pós-colheita e gestão, notou-se que a tecnologia de colheita teve maior índice tecnológico médio, o que explica a sua maior participação na composição do índice tecnológico geral $\left(I G_{3}\right)$, indicando que, os apicultores estiveram bem adaptados a essa tecnologia.

Ainda de acordo com os dados da Tabela 3, há necessidade de melhorar os índices tecnológicos de gestão, manejo e pós-colheita. O manejo eficiente das colméias é essencial para o sucesso na atividade. $\mathrm{O}$ apicultor deve estar sempre atento à situação das colméias, observando a quantidade de alimento disponível, a presença e a qualidade de postura da rainha, o desenvolvimento das crias, a ocorrência de doenças e pragas, o nível da temperatura no interior da colméia e o tamanho do enxame.

Na pós-colheita, deve-se dar ênfase às normas de higiene na manipulação e armazenamento do mel. A qualidade do produto depende dos cuidados que o apicultor adotar para evitar qualquer tipo de contaminação.

A tecnologia de gestão objetiva a capacidade administrativa do apicultor desde o processo de produção até a comercialização dos produtos.

O uso adequado das tecnologias de manejo e da pós-colheita são condições necessárias para as exigências do mercado internacional do mel natural de qualidade e livre de qualquer contaminação.

Considerando as tecnologias de produção $\left(I G_{1}\right), 75,26 \%$ dos apicultores entrevistados são classificados na categoria médio nível tecnológico, 20,62\%, na categoria alto nível e apenas $4,12 \%$ estão utilizando até $50 \%$ das tecnologias recomendadas, baixo nível tecnológico. 
668 - Desempenho da apicultura no estado do Ceará: competitividade, nível tecnológico e fatores condicionantes

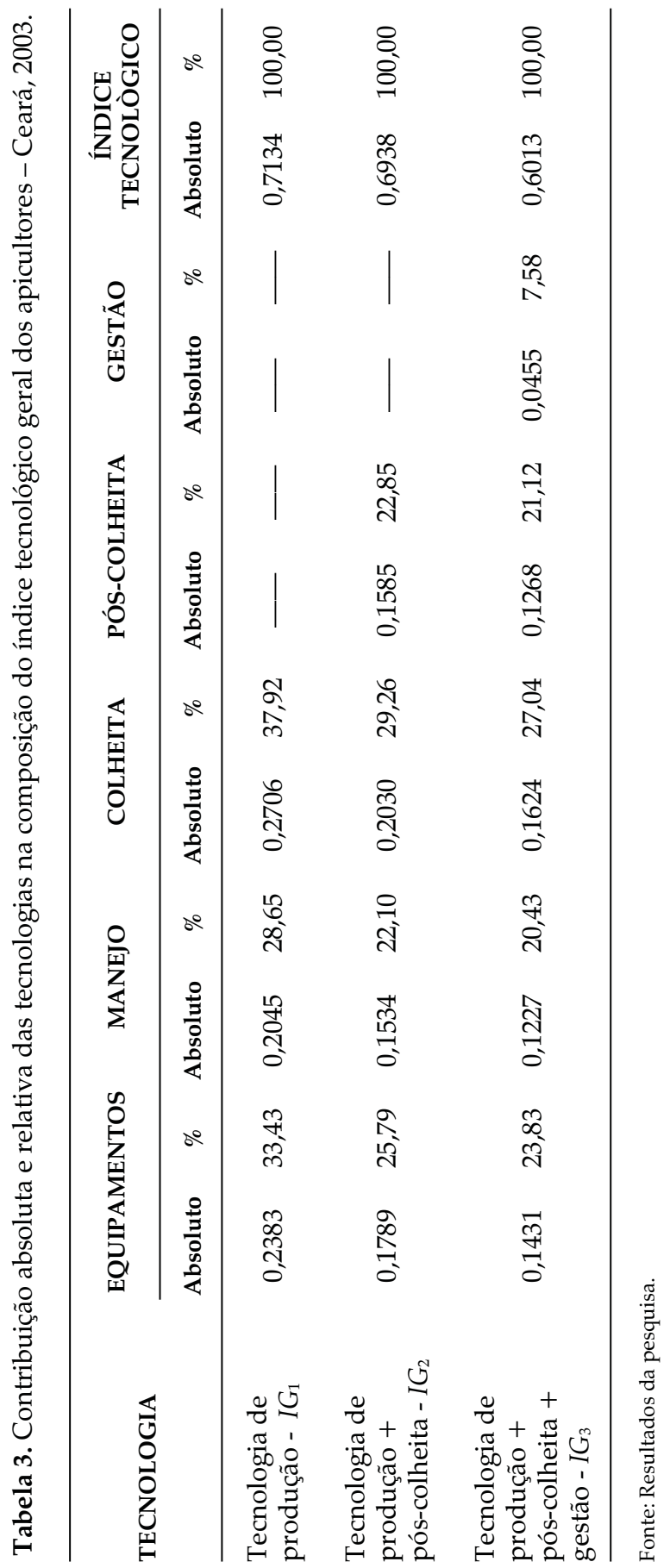


Após a inclusão da tecnologia de pós-colheita nas tecnologias de produção $\left(I G_{2}\right)$, notou-se que $21,65 \%, 68,04 \%$ e $10,31 \%$ dos apicultores são classificados, respectivamente, nas categorias alto, médio e baixo nível tecnológico. Finalmente, a inclusão das tecnologias de gestão no conjunto de tecnologias acima citadas alterou substancialmente a classificação dos apicultores segundo o uso de tecnologias recomendadas $\left(I_{3}\right)$ para a produção de mel natural no estado do Ceará. O baixo desempenho de apicultores em relação ao uso de variáveis que compõem estas tecnologias reduziu o índice tecnológico de todos os apicultores entrevistados.

\subsection{Influência das características socioeconômicas no nível tecnológico}

Nesta subseção, verifica-se a relação entre o nível tecnológico e as características socioeconômicas dos apicultores. A variável dependente do modelo assume valor igual a um (1) quando o índice tecnológico geral do apicultor $\left(I P_{j}\right)$ é maior que o índice geral da produção de mel natural $(I G)$.

Os coeficientes estimados para a amostra total e as suas respectivas estatísticas $t$ são mostrados na Tabela 4. Para a estimação do modelo, além das variáveis socioeconômicas, foram incluídas seis (6) variáveis Dummies com o objetivo de melhor captar os efeitos entre as variáveis explicativas e a variável explicada. Esse procedimento deve-se ao fato de a amostra total ser composta por apicultores entrevistados nos sete municípios selecionados e a amostra de cada município possuir características próprias.

De acordo com o modelo estimado, o nível tecnológico dos apicultores é função das variáveis grau de instrução, acesso à assistência técnica, acesso a financiamento e objetivo com a atividade. Os coeficientes dessas variáveis são positivos, indicando uma relação direta entre o nível tecnológico e as mesmas. Quanto maior o grau de instrução dos apicultores, o acesso à assistência técnica e ao financiamento, maior a probabilidade dos mesmos terem níveis tecnológicos mais elevados. Além disso, os apicultores para os quais a apicultura exerce a função de atividade principal têm maior probabilidade de ter níveis tecnológicos gerais acima do nível tecnológico geral da produção de mel natural encontrado para a amostra total. 
Tabela 4. Modelo estimado para o nível tecnológico dos apicultores em função das variáveis socioeconômicas - amostra total - Ceará, 2003.

\begin{tabular}{|c|c|c|c|c|c|}
\hline \multirow{2}{*}{$\begin{array}{c}\text { Variáveis } \\
\text { explicativas }\end{array}$} & \multirow{2}{*}{ Coeficientes } & \multirow{2}{*}{ Estatística $t$} & \multirow{2}{*}{ McFaddenR ${ }^{2}$} & \multicolumn{2}{|c|}{$\begin{array}{c}\text { Razão de Máxima } \\
\text { Verossimilhança (LR) }\end{array}$} \\
\hline & & & & $\begin{array}{c}\text { Estatística de } \\
\text { teste }\end{array}$ & $\chi_{\operatorname{tab}(10,5 \%)}^{2}$ \\
\hline Intercepto & $-1,2456$ & $-2,5362^{1}$ & \multirow{11}{*}{0,25654} & \multirow{11}{*}{34,4316} & \multirow{11}{*}{18,3070} \\
\hline GI & 0,3019 & $1,7030^{1}$ & & & \\
\hline AAT & 0,7515 & $2,5329^{1}$ & & & \\
\hline $\mathrm{AF}$ & 0,4545 & $1,2977^{2}$ & & & \\
\hline OA & 0,4036 & 1,1760 & & & \\
\hline SC & 0,3474 & 0,6319 & & & \\
\hline CR & $-1,9435$ & $-2,3596^{1}$ & & & \\
\hline $\mathrm{MO}$ & 0,5757 & 0,8824 & & & \\
\hline AS & 0,7750 & $1,2939^{2}$ & & & \\
\hline LN & $-0,0263$ & $-0,0441$ & & & \\
\hline PA & $-0,1676$ & $-0,2853$ & & & \\
\hline
\end{tabular}

Fonte: Dados da pesquisa.

GI - grau de instrução; AAT - acesso à assistência técnica; AF - acesso a financiamento; OA - objetivo com a atividade; SC - Santana do Cariri; CR - Crato; MO - Mombaça; AS - Alto Santo; LN - Limoeiro do Norte; e PA - Pacajus.

1 - Estatisticamente significante ao nível de $5 \%$ (teste unilateral).

2 - Estatisticamente significante ao nível de $10 \%$ (teste unilateral).

Os coeficientes das variáveis socioeconômicas, grau de instrução e acesso à assistência técnica são estatisticamente diferentes de zero ao nível de $5 \%$ de significância, enquanto o coeficiente da variável acesso a financiamento é ao nível de $10 \%$ de significância. Embora a variável objetivo com a atividade não tenha mostrado influência significativa sobre a variável dependente ao nível de $10 \%$, o valor do coeficiente estimado é maior que seu desvio padrão, não devendo ser desconsiderada. O modelo também revelou-se estatisticamente significativo ao nível de $5 \%$.

O teste do Multiplicador de Lagrange indicou não haver heterocedasticidade e, de acordo com o valor do McFadden $R^{2}$, o modelo estimado explica 25,65\% da variação da probabilidade do nível tecnológico dos apicultores ser maior ou igual ao nível tecnológico geral (médio). 


\subsection{Análise de Rentabilidade Financeira e de Competitividade}

\subsubsection{Análise de rentabilidade}

A presente análise dispõe de valores monetários médios de julho de 2007 expressos em reais $(\mathrm{R} \$)$ referentes à produção de $25 \mathrm{~kg}$ de mel natural. A receita bruta foi calculada levando-se em conta os preços médios desse produto, como produto principal, e da cera, como subproduto.

No cálculo do custo operacional total não foram considerados os custos com remuneração da terra. A apicultura é uma atividade que cria externalidades positivas para a agricultura por meio do aumento de sua produtividade devido à ação polinizadora das abelhas. Como não foram considerados os resultados dessas externalidades, em termos monetários, optou-se por não incluir o custo referente à remuneração da terra, como uma forma de compensação entre receita e custo.

$\mathrm{O}$ excelente desempenho da atividade foi revelado através dos indicadores como receita total, custo operacional efetivo (COE), custo operacional total (COT), custo de produção (CTP), margem bruta, ponto de nivelamento, lucro operacional e índice de lucratividade. A receita bruta, o COE, o COT e o CTP foram de R $\$ 154,89$, R $\$$ $33,56, R \$ 50,23$ e $R \$ 54,01$, respectivamente. O fluxo de caixa (dado pela diferença entre a receita bruta e o custo operacional total, não incluindo a depreciação) foi, em média, igual a R\$116,51, representando $75,22 \%$ da receita bruta.

Para a amostra total, a margem bruta em relação ao custo operacional efetivo $\left(\mathrm{MB}_{\mathrm{COE}}\right)$ foi igual a $361,45 \%$, indicando que os apicultores, em média, após pagarem os custos operacionais efetivos, ainda tinham recursos financeiros (para cobrir os demais custos) que equivaliam a quase quatro vezes o valor do custo operacional efetivo. A margem bruta em relação ao custo operacional total ( $\left.\mathrm{MB}_{\mathrm{COT}}\right)$ foi de $206,12 \%$, ou seja, pagando os custos operacionais totais, a disponibilidade de recursos para pagar os demais custos fixos, o risco e a capacidade empresarial, em média, correspondeu a aproximadamente o dobro do valor do custo operacional total. Efetuado o pagamento de todos os custos, não incluindo a remuneração ao risco e a capacidade empresarial, os apicultores obtiveram, em média, uma margem bruta em relação ao custo total da produção ( $\left.\mathrm{MB}_{\text {СтР }}\right)$ igual a $186,81 \%$.

Quanto aos pontos de nivelamento para o conjunto dos apicultores, foram necessárias as produções de 5,65 kg, 8,51 kg e 9,09 kg de mel natural para cobrir o custo operacional efetivo, o custo operacional total e o custo total de produção de $25 \mathrm{~kg}$ desse produto, respectivamente. O lucro operacional foi igual a $\mathrm{R} \$ 104,29$, ou seja, $67,33 \%$ da receita bruta.

A produção de mel natural no contexto da apicultura cearense mostrou-se bastante rentável, principalmente quando são obedecidas as recomendações técnicas que contribuem para os ganhos de produtividade e, por conseguinte, para o aumento do lucro. Esses resultados demonstram o grande potencial da apicultura e a sua viabilidade econômica, podendo contribuir para a qualidade de vida do pequeno produtor rural. 
Desempenho da apicultura no estado do Ceará: competitividade, nível tecnológico e fatores condicionantes

\subsubsection{Análise de competitividade}

Para a análise de competitividade, foram feitas comparações entre os apicultores entrevistados referentes ao custo unitário de produção de mel natural e ao índice de lucratividade. Quanto menor o custo unitário de produção e maior o índice de lucratividade, mais competitivo o apicultor. Dentre os apicultores, $87,63 \%$ obtiveram índice de lucratividade acima de 0,5. Esse resultado deve-se, em parte, ao elevado preço médio recebido pelo apicultor em 2003, como resultado da menor participação da China e da Argentina no total das exportações mundiais a partir de novembro de 2001, quando a União Européia suspendeu as importações chinesas e argentinas devido aos problemas causados por contaminação.

Preços altos resultam em maiores receitas brutas por quilograma, contribuindo para elevados lucros operacionais. No entanto, esse é só um dos fatores que compõem o lucro operacional. A competitividade dos apicultores não resulta somente da obtenção de maiores receitas brutas, mas também de menores custos unitários de produção. A receita bruta por quilograma de mel natural variou de $\mathrm{R} \$$ 5,43 a $R \$ 7,12$, com média igual a $R \$ 6,20$. O custo unitário de produção por quilograma de mel natural variou entre $R$ \$ 0,76 e $R$ \$ 4,98, com média de $R$ 2,16. Nota-se que $65,98 \%$ dos apicultores tiveram custo unitário de produção abaixo do valor médio. Assim, se reduções no preço médio do quilograma de mel natural reduzirem a receita média pela metade, mantidos os custos e a demanda constantes, a apicultura ainda será uma atividade rentável para 86,6\% dos apicultores.

Com a suspensão das restrições impostas aos chineses e aos argentinos, os preços do mel no mercado internacional devem ser reduzidos devido ao aumento da oferta. Todavia, o mel cearense tem características orgânicas e, por isso, é preferido pelos consumidores externos, assim, tal efeito terá uma influência pequena na rentabilidade da apicultura. Por outrolado, éimportante o emprego adequado das tecnologias recomendadas.

\subsection{Relação entre competitividade e nível tecnológico}

Nesta subseção, verifica-se a relação entre competitividade e nível tecnológico dos apicultores e espera-se que a mesma seja positiva. Como indicador de competitividade, usou-se o índice de lucratividade.

A equação estimada abaixo representa a relação entre competitividade $\hat{C}$ (índice de lucratividade) e o nível tecnológico geral do apicultor IG.

$$
\hat{C}=0,450439+0,370353 I G
$$

Verificou-se uma relação positiva e significativa ao nível de 0,01\% entre nível tecnológico geral do apicultor e competitividade. Então, quanto maior o nível tecnológico geral do apicultor maior a sua competitividade, visto que menor será o custo de produção unitário 


\section{Conclusões}

Os apicultores cearenses utilizaram, em média, 60,13\% das tecnologias recomendadas para a atividade. $\mathrm{O}$ menor nível tecnológico geral do apicultor correspondeu a 30,05\% dessas tecnologias e o maior, a $81,28 \%$. A tecnologia de colheita foi a que mais contribuiu para a composição do índice tecnológico geral $(27,04 \%)$, seguida das tecnologias de equipamento $(23,83 \%)$ e de pós-colheita $(21,12 \%)$. A menor contribuição coube a tecnologia de gestão $(7,58 \%)$.

A pesquisa constatou como variáveis condicionantes do nível tecnológico dos apicultores da amostra total, o grau de instrução, o acesso à assistência técnica, o acesso ao crédito e o objetivo com a atividade. Os coeficientes dessas variáveis são positivos, indicando uma reação direta entre o nível tecnológico e as mesmas. Assim, quanto maior o grau de instrução dos apicultores, o seu acesso à assistência técnica e ao crédito, maior a probabilidade dos mesmos terem níveis tecnológicos mais elevados.

Os indicadores de rentabilidade revelaram que a atividade apícola é bastante rentável. Essa rentabilidade pode aumentar por meio do uso adequado das tecnologias de manejo, pós-colheita e gestão.

O nível tecnológico é um fator determinante da competitividade dos apicultores. Isso indica que as inovações tecnológicas são imprescindíveis aos ganhos de lucratividade e competitividade desse setor. Logo, deve-se dar atenção especial ao fornecimento de assistência técnica, acesso a crédito, capacitação e treinamento dos apicultores e seus empregados.

\section{Referências Bibliográficas}

BARDY, L. P. C. Competitividade e Desenvolvimento Tecnológico. Visões Estratégicas. (2000).

BURKE, Thomas Joseph; MOLINA FILHO, José. Processo de Decisão Individual para Inovar: um Modelo Alternativo. Revista de Economia e Sociologia Rural. Brasília: SOBER, v.20, no 1, P 56-76, 1982. CD-ROM.

CARBAJAL, Alfio Celestino Rivera. Fatores Associados à Adoção de Tecnologias na Cultura do Caju: um estudo de caso. (Dissertação de Mestrado em Economia Rural) - UFC/CCA/DEA, Fortaleza, 1991.

COUTINHO, Luciano e FERRAZ, João Carlos. Estudo da competitividade da indústria brasileira. São Paulo: Papirus, 1995.

FARINA, E. M. M. Q.; e ZYLBERSZTAJN, D. Competitividade e Organização das Cadeias Agroindustriais. Costa Rica: Instituto Interamericano de Cooperação para a Agricultura, 63p. 1994. 
Desempenho da apicultura no estado do Ceará: competitividade, nível tecnológico e fatores condicionantes

FERRAZ, J. C.; HAGUERNAUER, Lia e KUPFER, David. Made in Brazil: desafios competitivos para a indústria. Rio de Janeiro: Campus, 1995.

FREITAS, Débora Gaspar Feitosa. Nível tecnológico e competitividade da produção de mel de abelhas (Apis mellifera) no Ceará. $101 \mathrm{f}$. (Dissertação de Mestrado em Economia Rural) - UFC/CCA/DEA, Fortaleza, 2003.

GUJARATI, Damodar N. Econometria Básica. 3 ed. São Paulo: Makron Books, 2000. 846 p.

HAGUENAUER, L., FERRAZ, J. C., KUPFER, D.S. (1996). Competição e Internacionalização na Indústria Brasileira. In: O Brasil e a Economia Global. Renato Baumann (org). Campus, Rio de Janeiro.

HICKS, J. R., The Theory of Wages. New York, MacMilian. (1936).

JUDGE, George G.; HILL, R. Carter; et al. Introduction to the Theory and Practice of Econometrics. 2a ed. Canadá: John Wiley \& Sons, 1988. 1024 p.

MATOS, V.D Apicultura no Estado do Ceará - competitividade, nível tecnológico e seus fatores condicionantes, produção e exportação de mel natural. 189f. (Dissertação de Mestrado em Economia Rural) - UFC/CCA/DEA, Fortaleza, 2005.

MESQUITA, Teobaldo Campos. Estudos de Economia Agrícola. Sobral: Edições UVA, 1998.

MIRANDA, E.A.de A. Inovações tecnológicas na Viticultura do sub-médio São Francisco. Recife: PIMES / UFPE, 2001. 191p. (Tese de Doutorado).

MONTEIRO, Manoel A. A.; LANDIM, José Roberto Medina; MOLINA FILHO, José. Cana-de-açúcar, Nível de Tecnologia e Nível de Vida. Revista de Economia e Sociologia Rural. Brasília: SOBER, 1980. CD-ROM.

PINHEIRO, A. C.; MOREIRA, A. R.B.; HORTA, M. E. Indicadores de competitividade das exportações: resultados setoriais para o período 1980/88. Rio de Janeiro:IPEA, 1992.

POSSAS, M.S. e,CARVALHO, E.G. Competitividade internacional: um enfoque teórico. In: CONGRESSO BRASILEIRO DE ECONOMIA E SOCIOLOGIA RURAL, 32, Brasília, 1994. Anais... Brasília: SOBER, 1994.p.1211-1229.

SANTOS, M. M. Fatores sócio-culturais e econômicos relacionados com a adotabilidade de práticas agropecuárias no estado de Minas Gerais. $142 \mathrm{f}$. (Dissertação Mestrado) - UFV. Viçosa, 1977. 
SEBRAE Informações de Mercado sobre Mel e Derivados da Colméia. Série Mercado. Serviço Brasileiro de Apoio às Micro e Pequenas Empresas, Brasília, março de 2006. Disponível em < http://homolog.portal.sebrae.com.br >.Acesso em 24 de junho de 2009.

SEREIA, V. J.; NOGUEIRA, J. M; CAMARA, M.R.G. da. As exportações paranaenses e a competitividade do complexo agroindustrial. In: CONGRESSO BRASILEIRO DE ECONOMIA E SOCIOLOGIA RURAL, 40, Passo Fundo, 2002. Anais...Brasília: SOBER, 2002. CD ROM.

SILVA, César Roberto Leite da. Inovações Tecnológicas e Distribuição de Renda: Impactos Distributivos dos Ganhos de Produtividade da Agricultura Brasileira. São Paulo: IEA, 1995. 245p. (Coleção Estudos Agrícolas 2).

SILVA, César Roberto Leite da; CARVALHO, Maria Auxiliadora de. Uma Análise dos Fatores que Determinam a Adoção de Tecnologia: Aplicação de um Modelo de Dados de Contagem nas Regiões de Ourinhos e Ribeirão Preto. São Paulo. In: CONGRESSO BRASILEIRO DE ECONOMIA E SOCIOLOGIA RURAL, 40, Passo Fundo, 2002. Anais... Passo Fundo: 2002. CD-ROM.

SMITH, Adam. A Riqueza das Nações: Investigação sobre sua natureza e suas causas. São Paulo: Abril Cultural, 1983. 2º v ( Coleção Os Economistas).

SOUZA, Francisca Laudeci. Estudo sobre o Nível Tecnológico da Agricultura Familiar no Ceará. 107 f. Dissertação (Mestrado em Economia Rural) UFC/CCA/DEA, Fortaleza, 2000.

STULP, V. J. Os impactos do Mercosul no setor agroindustrial e a pesquisa acadêmica no Brasil. In: CONGRESSO BRASILEIRO DE ECONOMIA E SOCIOLOGIA RURAL, 31 Ilhéus, 1993. Anais... Brasília: SOBER, 1993.p.929-941.

VICENTE, José Roberto. Determinação da Adoção de Tecnologia na Agricultura Paulista. In: CONGRESSO BRASILEIRO DE ECONOMIA E SOCIOLOGIA RURAL, 35, 1997, Natal. Anais... Natal 1997. Comunicações. CD-ROM. 